\title{
Results of surgical septal myectomy for obstructive hypertrophic cardiomyopathy: the Tufts experience
}

\author{
Hassan Rastegar, Griffin Boll, Ethan J. Rowin, Noreen Dolan, Catherine Carroll, James E. Udelson, \\ Wendy Wang, Philip Carpino, Barry J. Maron, Martin S. Maron, Frederick Y. Chen \\ Hypertrophic Cardiomyopathy Center and Research Institute, Divisions of Cardiology and Cardiothoracic Surgery, Tufts Medical Center, Boston, \\ MA, USA \\ Correspondence to: Hassan Rastegar, MD. HCM Center and Research Institute, Tufts Medical Center, 800 Washington St, Boston, MA 02111, USA. \\ Email: hrastegar@tuftsmedicalcenter.org.
}

\begin{abstract}
Background: For over 50 years, surgical septal myectomy has been the preferred treatment for drugrefractory heart failure symptoms in patients with obstructive hypertrophic cardiomyopathy (HCM). Over this time in the United States, the majority of myectomy operations have been performed in a small number of select referral centers.

Methods: We have taken the opportunity to report results from the relatively new Tufts HCM Center and surgical program, incorporated 13 years ago, during which 507 myectomies ( $52 \pm 14$ years of age; $56 \%$ male) were performed by one cardiothoracic surgeon, Dr. Hassan Rastegar.

Results: Resting left ventricular (LV) outflow gradients were reduced from $56 \pm 42 \mathrm{mmHg}$ preoperatively to $1.2 \pm 6.8 \mathrm{mmHg}$ on most recent echocardiogram $2.0 \pm 2.5$ years after surgery, and $94 \%$ of patients showed clinical improvement to NYHA functional class I or II. The first 200 myectomies were performed without mortality or major complications. Among all patients, 30-day mortality rate was $0.8 \%$. Over follow-up of $3.2 \pm 2.8$ years, 11 patients died (four due to HCM causes) with long-term survival after myectomy of $94 \%$ at 5 years (95\% CI: 89-96\%) and 91\% at 10 years (95\% CI: 84-95\%), which did not differ from the age- and gender-matched general U.S. population (log-rank $\mathrm{P}=0.9$ ).

Conclusions: This experience demonstrates that, with the appropriate support, new HCM surgical programs can provide patients successful relief of outflow obstruction, extended longevity and restored of quality of life.
\end{abstract}

Keywords: Hypertrophic cardiomyopathy (HCM); myectomy; heart failure; mitral valve

Submitted Feb 23, 2017. Accepted for publication May 15, 2017.

doi: 10.21037/acs.2017.07.07

View this article at: http://dx.doi.org/10.21037/acs.2017.07.07

\section{Introduction}

Left ventricular (LV) outflow tract obstruction is an important determinant of clinical course in hypertrophic cardiomyopathy (HCM) $(1,2)$, leading to progressive heart failure disability or morbidity in many patients. For 50 years, surgical septal myectomy (the Morrow procedure) (3-7) has been the "gold standard" treatment for drug-refractory heart failure symptoms in patients with obstructive HCM (8-12). This standard is supported by the 2011 U.S./Canada ACC/AHA guidelines $(13,14)$ placing myectomy as the preferred intervention for abolishing the outflow gradient, and relieving symptoms due to elevated $\mathrm{LV}$ systolic pressures and associated mitral regurgitation (15).

In North America, septal myectomy has been performed largely in select HCM centers-of-excellence with highly experienced cardiologists and cardiac surgeons (16-23). In this review, we have taken the opportunity to document the results of the select HCM surgical program at Tufts Medical Center (24). 


\section{Methods}

\section{Tufts surgical myectomy cohort}

Between the inception of the surgical center in October 2003 and December 2016, 507 patients underwent septal myectomy at Tufts Medical Center to relieve severe heart failure symptoms (usually equivalent to NYHA functional class III-IV) refractory to optimized medical management. All patients agreed to undergo surgery and accept its inherent risks to relieve their limiting symptoms which had become an obstacle to an acceptable quality of life. Among the 507 patients meeting inclusion criteria of having had septal myectomy at this center in the aforementioned time frame, there were 25 with severe aortic stenosis requiring concomitant valve replacement that have been excluded from the current study sample. The remaining 482 HCM patients who underwent septal myectomy were retrospectively reviewed and comprise the study cohort, including 30 patients that required adjunctive coronary artery bypass grafting (CABG).

To permit a minimum of 12 months follow-up, the 82 patients operated on during 2016 were excluded from the long-term survival analysis. Follow-up after surgery of the initial 400 patients was obtained by telephone contact or clinic visit, with a mean follow up time of $3.2 \pm 2.8$ years (range to 12.0 years). Of this group, 18 patients ( $4.5 \%$ ) have been lost to follow-up.

\section{Cardiac imaging}

\section{Left ventricular dimensions}

Imaging with 2-dimensional echocardiography and/or cardiovascular magnetic resonance (CMR) showed anterior ventricular septal thickness in the potential area of muscular resection, measuring $20 \pm 5 \mathrm{~mm}$ (range, $10-48 \mathrm{~mm}$ ). In 50 patients (11\%) septal thickness was $\leq 15 \mathrm{~mm}$ and in 22 patients $(5 \%)$ was $\geq 30 \mathrm{~mm}$. LV end-diastolic dimension was $41 \pm 6 \mathrm{~mm}$ (range, $25-72 \mathrm{~mm}$ ) and left atrial transverse dimension was $43 \pm 7 \mathrm{~mm}$ (range, 23-74 $\mathrm{mm}$ ). Mitral regurgitation was severe in 31 patients $(7 \%)$, mild to moderate in 299 (63\%), and absent/trace in 145 (30\%). LV ejection fraction was $\geq 50 \%$ in all patients (range, $45-80$ ).

\section{Operative procedure}

\section{Myectomy}

Prior to initiation of cardiopulmonary bypass, intraoperative transesophageal echocardiography (TEE) was performed to assess the extent and distribution of ventricular septal thickening, inspect mitral valve morphology, the degree and direction of mitral regurgitation, and subvalvular structures including papillary muscles, as well as provide measurements of the LV outflow tract gradient at rest and with provocation with intravenous isoproterenol or dobutamine.

After cardiopulmonary bypass was established, a transverse aortotomy was created and ventricular muscular resection typically began $1 \mathrm{~cm}$ below the nadir of the right coronary cusp and the commissure between the left and right cusps, and was extended distally between these two lines down to the mid-ventricle. The degree of muscular resection was dependent on the distribution and thickness of the basal septum. Any abnormal intraventricular muscle bundles or accessory connections to the mitral valve were resected. In patients with direct insertion of anomalous anterolateral papillary muscle onto anterior mitral leaflet, septal myectomy was extended beyond the contact point of the papillary muscle and ventricular septum, and adjunctive surgical debulking of the papillary muscle was done to eliminate potential for mid-ventricular obstruction.

To ensure complete relief of subaortic obstruction, 80 patients $(17 \%)$ required mitral valve plication, effectively shortening an elongated anterior mitral leaflet. Mitral ring annuloplasty $(n=22)$ or valve replacement $(n=1)$ was performed in patients with severe mitral regurgitation judged to be caused by intrinsic valve pathology.

After the patient was separated from cardiopulmonary bypass, intraoperative TEE at rest and with provocation with isoproterenol or dobutamine was done to confirm complete relief of obstruction and resolution of mitral regurgitation. Indications to resume cardiopulmonary bypass and perform additional muscular resection and/ or mitral valve intervention included: residual mitralseptal contact with gradient $>30 \mathrm{mmHg}$ and/or $\geq 2+$ mitral regurgitation.

\section{Cox-Maze procedure}

In all patients with a history of atrial fibrillation, the Cox-maze IV procedure was carried out. The bilateral pulmonary veins were encircled and ablated with a bipolar radiofrequency clamp. The left atrial appendage was opened and the trabecular segment was removed. Through a left atriotomy, bipolar radiofrequency clamps were used to make connecting lesions between the right and left pulmonary veins (Box lesion). Epicardially, a cryoprobe was placed over coronary sinus at $\mathrm{P} 3$ of mitral valve to create an ice 
ball and a connecting lesion was created between the right pulmonary veins, ice ball, and mitral valve annulus. Right atrial lesions were placed via a small vertical atriotomy. With a bipolar clamp, a lesion was created between the superior and inferior vena cavae. Then, with cryoprobe a linear lesion was created from upper pole of atriotomy and tricuspid annulus.

\section{Statistical analysis}

Continuous and categorical data are expressed as mean $( \pm$ $\mathrm{SD})$ and $\mathrm{n}(\%)$, respectively. Comparisons of characteristics between groups were made with unpaired Student's $t$-test, one way ANOVA, Chi-square tests, or Fisher's Exact test where appropriate for continuous and categorical data. A P value of $<0.05$ was considered statistically significant. The survival analysis model used proportional hazards regression methodology and Kaplan-Meier survival curves were compared using log-rank statistics. End points were allcause mortality and HCM-related mortality. Deaths within 30 days or during the index hospitalization after myectomy were considered operative deaths and are included in both end points. The HCM-mortality included sudden cardiac death (unexpected within one hour of witnessed collapse or nocturnal) or heart failure death (in the context of progressive cardiac decompensation).

For comparison with myectomy patients, an expected survival curve for the general population was generated from U.S. Health Statistics, which incorporate all-cause mortality. Each myectomy patient was matched to the U.S. white population by age, gender, and year of study entry. All analyses were performed with SAS 9.3 (SAS Institute, Cary, NC).

\section{Results}

\section{Demographic and clinical findings}

At the time of operation, patients were $52 \pm 14$ years of age (range, $12-82$ years), with 42 patients $(9 \%)<30$ years and $151(31 \%)>60$ years of age; $273(57 \%)$ were male. LV outflow gradients of $\geq 50 \mathrm{mmHg}$ (range to $170 \mathrm{mmHg}$ ) were present in 282 patients $(60 \%)$, and in the remaining 200 patients $(40 \%)$ was $<50 \mathrm{mmHg}$ at rest but $\geq 50 \mathrm{mmHg}$ with physiologic (exercise) provocation (range to 180).

Heart failure symptoms consistent with NYHA class III or IV based on personal functional capacity deficits, including exertional dyspnea and/or chest pain during daily activities, were present in 473 patients. Nine additional patients in class I or II underwent surgery for patient preference $(n=7)$, or need for concomitant CABG for severe multi-vessel coronary artery disease $(n=1)$, or left atrial myxoma resection $(\mathrm{n}=1)$ (Table 1).

\section{Postoperative hemodynamic results}

Resting LV outflow gradients were reduced from $56 \pm$ $42 \mathrm{mmHg}$ preoperatively, to $1.2 \pm 7 \mathrm{mmHg}$ on most recent echocardiogram $2.0 \pm 2.5$ years after surgery. In the 31 patients with preoperative severe mitral regurgitation (3 or $4+$ ), postoperatively $27(87 \%)$ had no or mild mitral regurgitation and four (13\%) had residual moderate mitral regurgitation, including $22(71 \%)$ who required insertion of a mitral valve annular ring and $1(3 \%)$ with mitral valve replacement. During follow-up, no patient underwent repeat surgical myectomy for persistent or recurrent outflow tract gradient.

\section{Short-term complications and operative mortality}

Of the 482 patients, 4 (0.8\%) died within 30 days of surgery or during the index hospitalization. These patients were 24, 50,71 and 82 years of age and two were male. Causes of death were: cardiogenic shock due to low cardiac output in two patients, pericardial tamponade and multi-organ failure in one patient, and respiratory failure in one patient.

A total of 43 patients required postoperative implantation of a permanent dual-chamber pacemaker for complete heart block. Pacemakers were placed in four patients for reasons other than complete heart block including seconddegree heart block for two, an asystolic episode for one, and symptomatic bradycardia for one. Ninety patients $(4.0 \%$ overall) had complete heart block with no risk markers for development of postoperative complete heart block. The remaining 24 had predisposing conditions or surgical procedures increasing the risk for development of complete heart block, including: mild hypertrophy of basal septum $\leq 15 \mathrm{~mm}(\mathrm{n}=7)$; preoperative right bundle branch block $(\mathrm{n}=5)$; concomitant septal muscular resection at time of subaortic membrane removal $(n=4)$; Cox-Maze procedure $(n=4)$; aortic valve debridement $(\mathrm{n}=1)$; preoperative congenital $\operatorname{VSD}(\mathrm{n}=1)$; myxoma resection $(\mathrm{n}=1)$ and resection of crista supraventricular muscle to relieve right ventricular outflow tract obstruction $(\mathrm{n}=1)$.

Iatrogenic VSD occurred in five patients. Maximal anterior septal thickness was $16-17 \mathrm{~mm}$ in three patients 


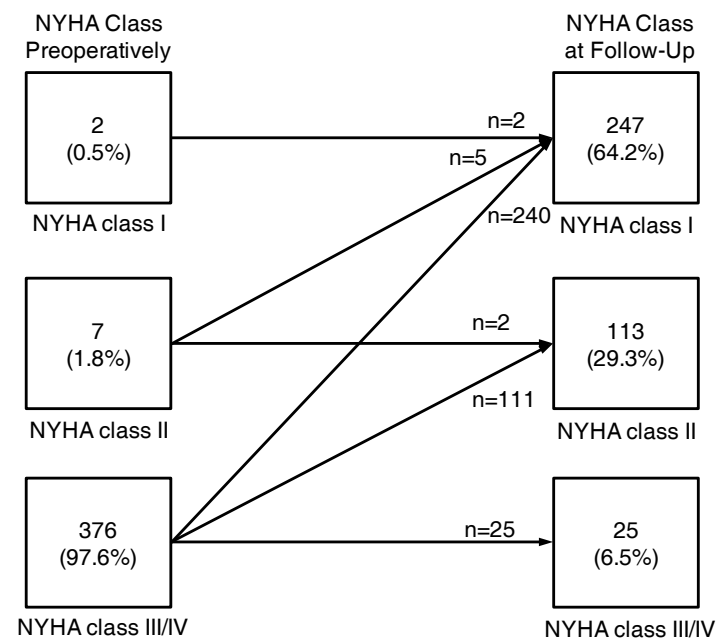

Figure 1 Comparison of NYHA functional classification for myectomy patients at preoperative and most-recent follow-up evaluation. NYHA, New York Heart Association.

and 18 and $20 \mathrm{~mm}$ in the other two. Intraoperative repair with septal patch was required in one patient, while the remaining four VSDs were considered not to be of clinical significance and were not repaired. Of the five patients with VSD, all have remained asymptomatic or mildly symptomatic, and none have required VSD repair during the follow-up period.

Ischemic stroke occurred in four patients in the perioperative period, including two patients with acute onset upper extremity weakness, one with expressive aphasia, and one with a left parietal infarct confirmed on CT obtained for altered mental status with no neurologic deficits. None of these incidents occurred in the setting of perioperative atrial fibrillation. Postoperative atrial fibrillation occurred in 101 patients $(21 \%)$, including 14 with preoperative atrial fibrillation that underwent COX-Maze procedure at the time of septal myectomy. Cardioversion occurred spontaneously $(\mathrm{n}=2)$ or was achieved with beta-blockade $(\mathrm{n}=3)$, amiodarone $(\mathrm{n}=71)$ or electrical cardioversion $(\mathrm{n}=23)$. The remaining two were rate-controlled at time of discharge.

\section{Long-term outcome}

Of the 396 patients eligible for long-term follow-up, 385 (96.3\%) were alive at most recent follow-up. Of these 247 (64\%) were asymptomatic in NYHA class I, 113 (29\%) were in class II with mild symptoms, and 25 (7\%) had persistent limiting class III-IV symptoms (Figure 1). The extent of functional improvement was similar in patients with preoperative rest obstruction compared to those with only exercise-induced gradients [208 (92\%) class I-II for rest obstruction vs. 141 (95\%) class I-II for provocable obstruction; $\mathrm{P}=0.3]$. There was also no difference with respect to gender [205 (93\%) class I-II for males vs. 155 (94\%) class I-II for females; $\mathrm{P}=0.8$ ] (Table 2).

Late deaths occurred in 11 patients at $59 \pm 15$ years of age, $3.5 \pm 1.7$ years after myectomy. Three of the deaths were due to HCM-related causes: two patients who developed end-stage heart failure and systolic dysfunction (who were not candidates for heart transplant), and one patient with sudden death but without conventional risk factors. The eight other deaths were due to non-cardiac etiologies: three with multiple co-morbidities, one from cancer, one from illicit drug use, and one from mesenteric ischemia. Cause of death in two patients is unknown.

Overall long-term survival after myectomy was $98 \%$ at 1 year (95\% CI: $96-99 \%), 94 \%$ at 5 years $(95 \%$ CI: $89-96 \%)$ and $91 \%$ at 10 years (95\% CI: $84-95 \%$ ), and did not differ from the age- and gender-matched general U.S. population (log-rank $\mathrm{P}=0.9$ ) (Figure 2). HCM-related mortality after myectomy was $98 \%$ at one year $(95 \%$ CI: 96-99\%), $97 \%$ at 5 years (95\% CI: $94-99 \%$ ) and $97 \%$ at 10 years (95\% CI: 94-98\%), and was significantly higher than the age- and gender-matched general U.S. population ( $\log$-rank $\mathrm{P}=0.04)$ (Figure 3).

\section{Prior alcohol septal ablation}

Twelve patients (3\%) had myectomy performed after alcohol septal ablation due to recurrent heart failure symptoms (NYHA class III) caused by persistent outflow tract obstruction. Post-myectomy, none of these 12 patients had a significant outflow gradient $(\geq 50 \mathrm{mmHg})$ on most recent echocardiographic evaluation and all improved to class I $(n=8)$ or II $(n=4)$ on most recent follow-up.

\section{Discussion}

The HCM Institute and surgical myectomy program at Tufts Medical Center is now 13 years old, the largest such program in the eastern United States, and the third largest in the world. Since its inception, a single cardiothoracic surgeon, Dr. Hassan Rastegar, has performed surgical septal myectomy on more than 500 severely symptomatic drugrefractory patients with obstructive HCM to relieve outflow 


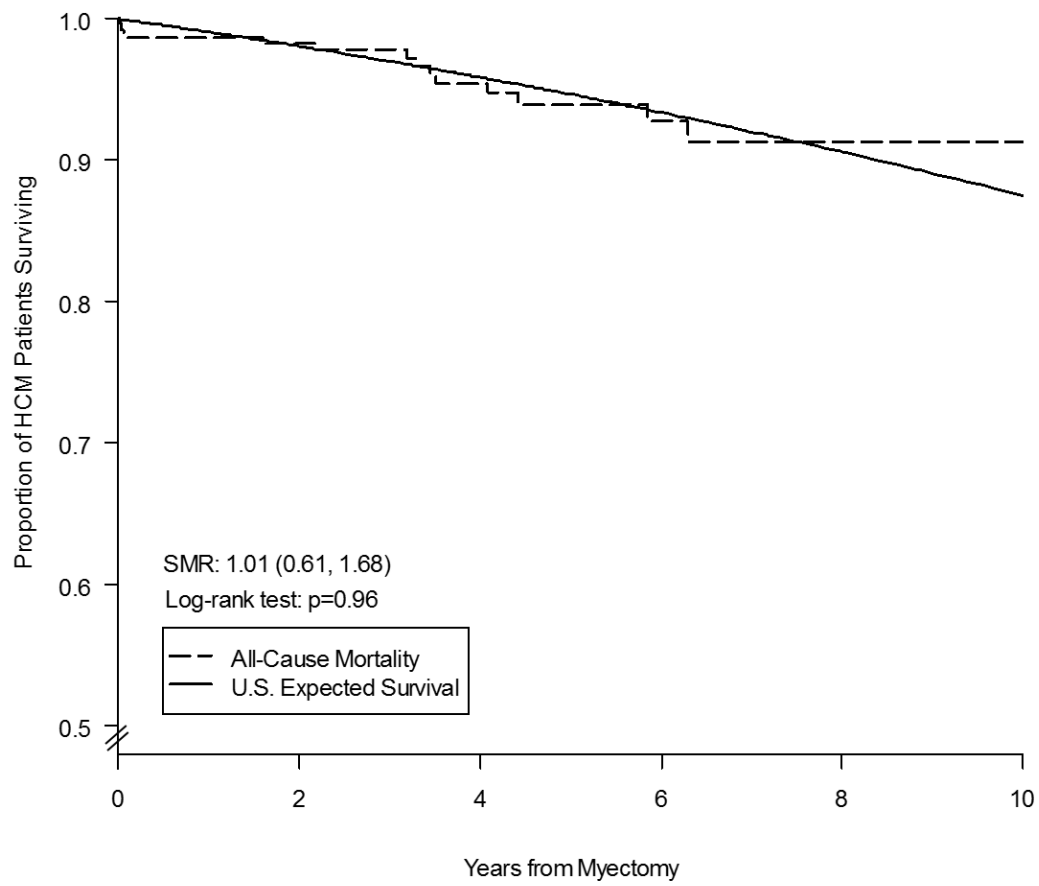

Figure 2 Survival free from all-cause mortality after surgical myectomy for 482 patients with obstructive HCM compared with an age and gender-matched general U.S. white population. SMR, standardized mortality ratio.

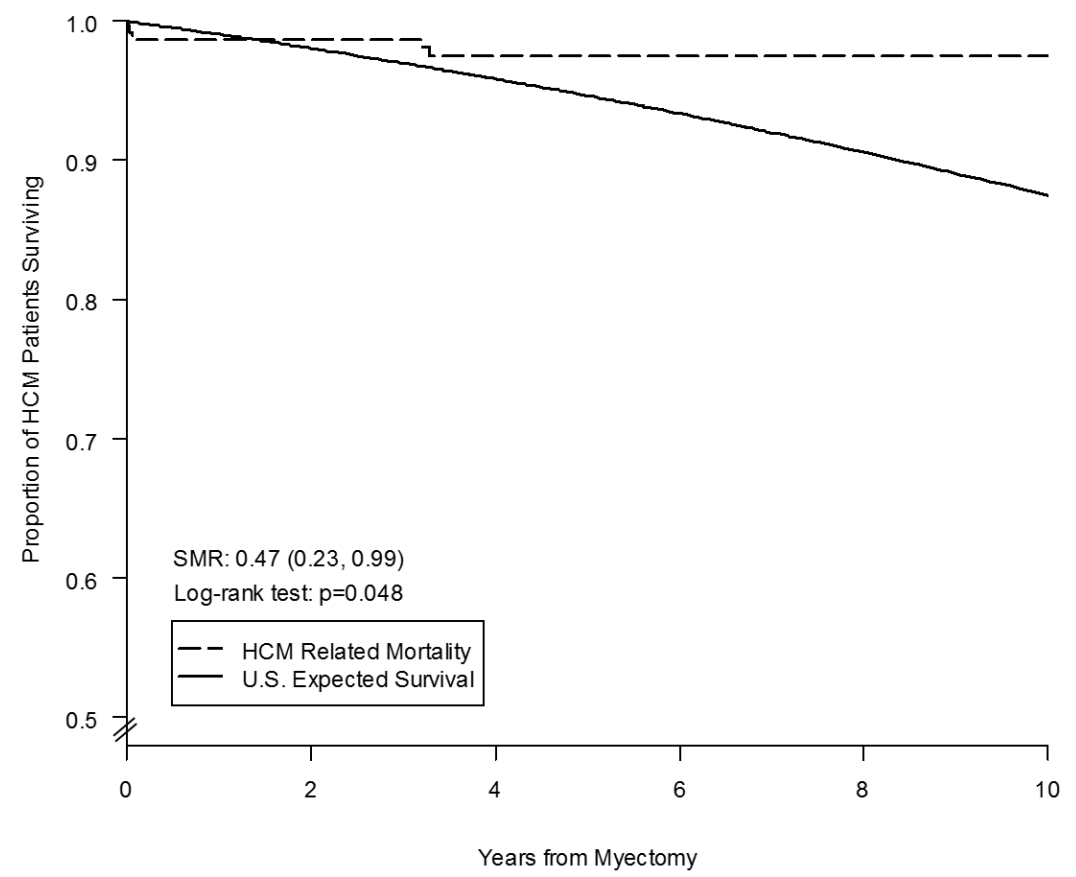

Figure 3 Freedom from HCM-related mortality after surgical myectomy for obstructive HCM in 482 patients. SMR, standardized mortality ratio. 


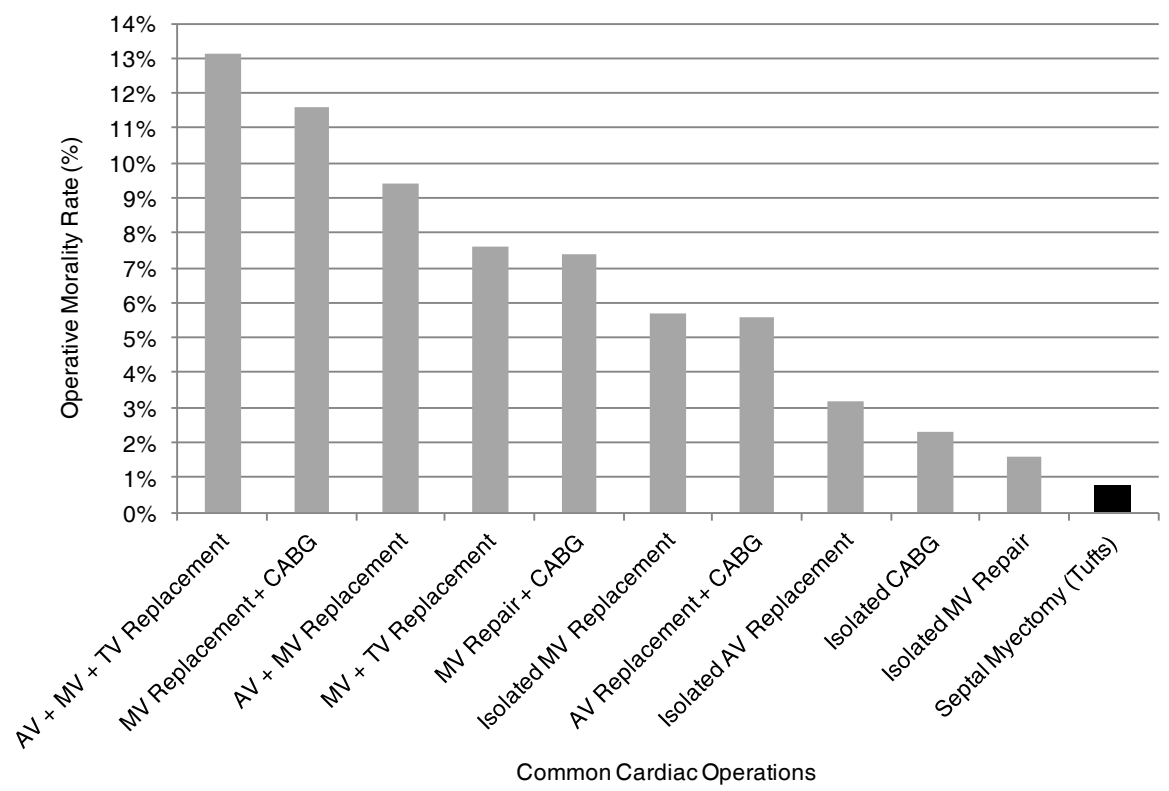

Figure 4 Comparison of operative mortality rates for septal myectomy with other common cardiac surgical procedures as reported by the Society of Thoracic Surgeons (STS) (26-29). AV, aortic valve; MV, mitral valve; TV, tricuspid valve; CABG, coronary artery bypass graft.

gradient and reverse heart failure morbidity and mortality.

Hemodynamic and clinical results and operative mortality at Tufts are consistent, in all respects, with the experience at other established HCM centers with longstanding myectomy programs (16-23). For example, LV outflow obstruction was essentially obliterated with small postoperative gradients at rest of $1.2 \pm 6.8 \mathrm{mmHg}$, operative mortality was $0.8 \%$, and $94 \%$ of patients showed clinical improvement to NYHA functional class I or II due to normalization of intraventricular $\mathrm{LV}$ pressures and decrease in associated mitral regurgitation. In addition, clinical improvement following myectomy was comparable among patients with rest-compared to provocable-obstruction, similar to previous surgical experiences. Therefore, it is important to underscore that when performed by a highly experienced surgeon, myectomy consistently reverses the heart failure process and usually returns patients to normal (or near-normal) activity level and quality of life. A small subgroup of clinical non-responders to myectomy were identified, defined as patients with persistent NYHA class III symptoms postoperatively despite surgical relief of the outflow gradient. The determinants of this clinical course remain incompletely resolved, but may be due to the predominant role played by diastolic dysfunction in generating symptoms.

This contemporary surgical series and initiative from Tufts Medical Center underscores the important transformation of septal myectomy from a highly morbid operation (25) to one of the safest open-heart procedures, currently with a low operative mortality of $<1 \%$ at experienced centers (16-23). Notably, the operative mortality associated with surgical myectomy at Tufts Medical Center is significantly lower compared to that of a number of other common cardiovascular operations as reported by the Society of Thoracic Surgeons, including an operative risk 9-fold less than CABG with concomitant mitral valve replacement and 2-fold less than isolated aortic valve replacement (Figure 4) (26-29).

Furthermore, long-term survival from all-causes following myectomy is high $(94 \%$ at 5 years; $91 \%$ at 10 years), equivalent to that of the general U.S. population. It is also reasonable to assume that heart failure would have inevitably progressed to death and/or profound disability. By virtue of relieving impedance to outflow and normalizing $L V$ pressures and mitral regurgitation, these data substantiate that myectomy conveys a survival benefit.

In the Tufts experience reported here, there is little evidence to substantiate a "learning curve" in performing the myectomy operation (30). Indeed, the first 200 myectomy operations were performed without mortality or major complications, with no outstanding differences with subsequent patients regarding operative metrics, extent 
Table 1 Baseline clinical and imaging demographics, and postoperative outcomes in 482 obstructive HCM patients undergoing surgical myectomy

\begin{tabular}{|c|c|}
\hline Characteristic & Value $(n=482)$ \\
\hline \multicolumn{2}{|l|}{ Demographics } \\
\hline Male & $273(56.6)$ \\
\hline Age at myectomy (years) & $52.1 \pm 14.3$ \\
\hline Age $<30$ years at time of surgery & $42(8.7)$ \\
\hline Age $\geq 60$ years at time of surgery & $151(31.3)$ \\
\hline \multicolumn{2}{|l|}{ Transthoracic echocardiography } \\
\hline LVOT resting gradient $(\mathrm{mmHg})$ & $56.4 \pm 42.4$ \\
\hline LVOT resting gradient $30-49 \mathrm{mmHg}$ & $53(11.3)$ \\
\hline LVOT resting gradient $\geq 50 \mathrm{mmHg}$ & $282(60.0)$ \\
\hline Maximum LV thickness (mm) & $20.1 \pm 4.7$ \\
\hline Maximum LV thickness $\leq 15 \mathrm{~mm}$ & $50(10.7)$ \\
\hline Maximum LV thickness $\geq 30 \mathrm{~mm}$ & $22(4.7)$ \\
\hline LV ejection fraction (\%) & $65.6 \pm 4.0$ \\
\hline Left atrial dimension (mm) & $42.9 \pm 7.3$ \\
\hline LVED (mm) & $40.5 \pm 5.8$ \\
\hline \multicolumn{2}{|l|}{ Contrast-CMR } \\
\hline CMR studies & $302(63.2)$ \\
\hline Presence of LGE & $183(66.3)$ \\
\hline \multicolumn{2}{|l|}{ Risk Factors } \\
\hline Family history of $\mathrm{HCM}$ & $114(24.3)$ \\
\hline Family history HCM-related sudden death & $41(8.6)$ \\
\hline NSVT on Holter monitor & $43(9.0)$ \\
\hline History of Syncope & $70(14.6)$ \\
\hline \multicolumn{2}{|l|}{ NYHA functional classification } \\
\hline 1 & $2(0.4)$ \\
\hline II & $7(1.5)$ \\
\hline III & $469(97.3)$ \\
\hline IV & $4(0.8)$ \\
\hline \multicolumn{2}{|l|}{ Preoperative comorbidities and interventions } \\
\hline Atrial fibrillation & $180(37.5)$ \\
\hline Paroxysmal & $166(34.4)$ \\
\hline Permanent/persistent & $14(2.9)$ \\
\hline Previous alcohol septal ablations & $12(2.5)$ \\
\hline Previous ICD implantation & $84(17.4)$ \\
\hline Appropriate ICD interventions & $12(14.3)$ \\
\hline Resuscitated cardiac arrest & $2(0.4)$ \\
\hline
\end{tabular}

\begin{tabular}{|c|c|}
\hline Characteristic & Value $(n=482)$ \\
\hline \multicolumn{2}{|l|}{ Drug therapy } \\
\hline Beta-blockers & $337(70.4)$ \\
\hline Calcium channel blockers & $172(35.9)$ \\
\hline Disopyramide & $32(6.7)$ \\
\hline Amiodarone & $13(2.7)$ \\
\hline ACE inhibitor/ARB & $72(15.0)$ \\
\hline Diuretics & $88(18.4)$ \\
\hline Anticoagulants & $47(9.8)$ \\
\hline Warfarin & $39(8.1)$ \\
\hline Novel oral anticoagulants & $8(1.7)$ \\
\hline \multicolumn{2}{|l|}{ Genetic testing } \\
\hline MYBPC3 & $14(2.9)$ \\
\hline MYH7 & $5(1.0)$ \\
\hline TNNT2 & $2(0.4)$ \\
\hline MYHC & $1(0.2)$ \\
\hline MYHC7 + MYBPC & $1(0.2)$ \\
\hline \multicolumn{2}{|l|}{ Operative details and concomitant procedures } \\
\hline Isolated myectomy & $347(72.0)$ \\
\hline Cox-maze procedure & $83(17.2)$ \\
\hline Coronary artery bypass grafting & $30(6.2)$ \\
\hline Mitral annuloplasty & $21(4.4)$ \\
\hline Mitral valve replacement & $1(0.2)$ \\
\hline Subaortic membrane resection & $10(2.1)$ \\
\hline Aortic valve repair or replacement & $5(1.0)$ \\
\hline Other procedures & $15(3.1)$ \\
\hline Need for repeat cardiopulmonary bypass run & $52(10.8)$ \\
\hline \multicolumn{2}{|l|}{ Perioperative events } \\
\hline Atrial fibrillation & $101(21.0)$ \\
\hline Complete heart block & $19(4.0)^{\star}$ \\
\hline Stroke & $4(0.8)$ \\
\hline Ventricular septal defect & $5(1.0)$ \\
\hline Renal failure requiring hemodialysis & $1(0.2)$ \\
\hline 30-day operative mortality & $4(0.8)$ \\
\hline Postoperative length of stay (d) & $6.2 \pm 3.1$ \\
\hline \multicolumn{2}{|c|}{$\begin{array}{l}\text { Data are shown as } \mathrm{n}(\%) \text { or mean } \pm \text { SD. *, excludes patient with } \\
\text { predisposing conditions or adjunctive surgical interventions judged to } \\
\text { increase risk for complete heart block. LVOT, left ventricular outflow } \\
\text { gradient; LV, left ventricle; LVED, left ventricle at end diastole; CMR, } \\
\text { cardiac magnetic resonance; LGE, late gadolinium enhancement; } \\
\text { NSVT, non-sustained ventricular tachycardia; NYHA, New York } \\
\text { Heart Association; ICD, implantable cardioverter defibrillator; ACE, } \\
\text { angiotensin-converting enzyme; ARB, angiotensin II receptor blocker; } \\
\text { MYBPC3, myosin-binding protein C; MYH7, myosin heavy chain 7; } \\
\text { TNNT, troponin T; MYHC, myosin heavy chain. }\end{array}$} \\
\hline
\end{tabular}


Table 2 Echocardiographic and clinical outcomes of patients with obstructive HCM undergoing myectomy

\begin{tabular}{|c|c|}
\hline Variables & Outcomes \\
\hline \multicolumn{2}{|l|}{ Postoperative echocardiogram } \\
\hline LVOT resting gradient $(\mathrm{mmHg})$ & $0.6 \pm 5.4$ \\
\hline LVOT resting gradient $30-49 \mathrm{mmHg}$ & $2(0.5)$ \\
\hline LVOT resting gradient $\geq 50 \mathrm{mmHg}$ & $2(0.5)$ \\
\hline LV ejection fraction (\%) & $59.7 \pm 6.3$ \\
\hline LV ejection fraction $<50 \%$ & $17(4.1)$ \\
\hline Left atrial dimension (mm) & $41.8 \pm 6.7$ \\
\hline \multicolumn{2}{|l|}{ Most recent echocardiography ${ }^{\star *}$} \\
\hline LVOT resting gradient $(\mathrm{mmHg})$ & $1.2 \pm 6.8$ \\
\hline LVOT resting gradient $30-49 \mathrm{mmHg}$ & $6(1.3)$ \\
\hline LVOT resting gradient $\geq 50 \mathrm{mmHg}$ & $3(0.7)$ \\
\hline LV ejection fraction (\%) & $58.9 \pm 7.2$ \\
\hline LV ejection fraction $<50 \%$ & $25(5.6)$ \\
\hline Left atrial dimension (mm) & $41.7 \pm 6.8$ \\
\hline \multicolumn{2}{|l|}{ Most recent drug therapy** } \\
\hline Beta-blockers & $363(76.7)$ \\
\hline Calcium channel blockers & $66(14.0)$ \\
\hline Disopyramide & $2(0.4)$ \\
\hline Amiodarone & $46(9.7)$ \\
\hline ACE inhibitor/ARB & 94 (19.9) \\
\hline Diuretics & $164(34.7)$ \\
\hline Anticoagulants & $87(18.2)$ \\
\hline Warfarin & $63(13.3)$ \\
\hline Novel oral anticoagulants & $24(5.0)$ \\
\hline \multicolumn{2}{|l|}{ Most recent follow up ${ }^{\star \star}$} \\
\hline Follow up time (years) & $3.2 \pm 2.8$ \\
\hline Age at last follow-up (years) & $55.2 \pm 14.8$ \\
\hline Alive & $385(96.3)$ \\
\hline \multicolumn{2}{|l|}{ NYHA functional classification ${ }^{\star *}$} \\
\hline I & $247(64.2)$ \\
\hline II & $113(29.3)$ \\
\hline III & $21(5.5)$ \\
\hline IV & $4(1.0)$ \\
\hline
\end{tabular}

Data are shown as $\mathrm{n}(\%)$ or mean $\pm \mathrm{SD}$. ${ }^{* *}$, includes only initial 400 patients operated on prior to 2016. LVOT, left ventricular outflow gradient; LV, left ventricle; LVED, left ventricle end diastole; ACE, angiotensin-converting enzyme; ARB, angiotensin II receptor blocker. of gradient reduction, or symptomatic relief. These data argue that it is possible to initiate a new myectomy program within an HCM environment that will ultimately prove to be safe and effective (as Tufts did 13 years ago), and create what is now a large high volume center caring for 3,000 patients. As a pertinent historical note, the Tufts myectomy program, now one of the largest in North America, was created in 2003 as part of a new HCM center with the support of Dr. Joseph Dearani (Mayo Clinic) who served as an early mentor to Dr. Rastegar.

Since the inception of the Tufts myectomy program, extended myectomy was adopted as the operative approach of choice, while simultaneously recognizing the contribution of mitral valve morphology and associated intraventricular muscular structures to outflow obstruction. In this regard, pre-surgical planning is performed routinely with cardiac imaging, including exercise echocardiography and CMR, with particular focus on the pattern and extent of ventricular septal hypertrophy, mitral valve structure and submitral morphology.

With the information obtained by preoperative and intraoperative imaging, as well as the surgeon's direct visualization during the myectomy, LV outflow tract structures judged to be contributing to obstruction prompted additional operative procedures, including revision of hypertrophied and abnormally displaced papillary muscles, resection of accessory LV apicalbasal muscle bundles, and cutting of chordal connections $(5,31)$. In addition, congenital direct anomalous insertion of papillary muscle into the anterior mitral leaflet in the absence of chordae tendinae producing mid-cavitary outflow obstruction was identified intraoperatively, requiring muscular resection of the septum distal to the point of apposition and obstruction (5,32,33).

In a small subset of patients, the anterior mitral leaflet was particularly elongated, resulting in the site of subaortic obstruction displaced distally in the LV more than usual even after adequate muscular septal resection. In these patients, the mitral leaflet was plicated to stiffen the leaflet, eliminate mobility of the valve and decrease systolic anterior motion (SAM). Addition of these techniques to the extended muscular resection assured abolition of the outflow gradient.

All myectomy operations were conducted using intraoperative TEE, often employing gradient provocation with dobutamine or isoproterenol. This was completed both prior to initiating cardiopulmonary bypass to determine baseline measurements of gradient and degree 
of mitral regurgitation, as well as after muscular resection off bypass to assess efficacy of the myectomy, confirm absence of mitral-septal contact and eliminate outflow obstruction. Intraoperative TEE before myectomy was also useful in clarifying the distribution and extent of ventricular septal thickening. This provides the surgeon with an accurate 'road map' for planning the depth and extent of muscular resection necessary to achieve optimal relief of outflow obstruction. In a small subset of patients (11\%), intraoperative TEE findings demonstrated that it was necessary to reconstitute cardiopulmonary bypass for additional muscular septal resection or mitral interventions.

Evolution of the Tufts program addresses an unmet need in the contemporary management of this disease by partially closing the disparity between the number of obstructive HCM patients deserving of myectomy and the available number of surgeons experienced with this operation. This issue has been highly visible recently, given recognition that myectomy mortality rates in the practicing community outside of HCM centers can be as high as $6 \%$ $(34,35)$, triggering a call for more cardiac surgeons to gain experience specifically with this operation and become available to the HCM patient population in high volume settings (35).

\section{Limitations}

Postoperative echocardiograms were performed under basal conditions and therefore it was not possible to compare magnitude of gradient reduction among those HCM patients with pre-operative exercise-induced outflow tract gradients. However, the observation that heart failure symptoms were improved to a similar degree among HCM patients with rest versus provocable obstruction, suggests that clinically significant residual (post-operative) provocable gradients were not present. In addition, given the clinical and technical expertise involved with surgical management of obstructive HCM patients, our results might not be generalizable to centers performing myectomy at a lower volume.

In conclusion, over a relatively short period of 13 years, the HCM center at Tufts Medical Center has performed surgical myectomy in over 500 patients with obstructive HCM with excellent results comparable to surgical centers with longer experience with myectomy. Through this initiative, the natural history of many HCM patients have benefited substantially, including the aspiration for successful relief of outflow obstruction, extended longevity and restored quality of life. This experience provides precedent for future efforts creating new HCM programs to expand the access to surgical myectomy for obstructive HCM patients in the United States and internationally $(36,37)$.

\section{Acknowledgements}

None.

\section{Footnote}

Conflicts of Interest: The authors have no conflicts of interest to declare.

\section{References}

1. Maron MS, Olivotto I, Zenovich AG, et al. Hypertrophic cardiomyopathy is predominantly a disease of left ventricular outflow tract obstruction. Circulation 2006;114:2232-39.

2. Maron BJ, Maron MS, Wigle ED, et al. The 50-year history, controversy, and clinical implications of left ventricular outflow tract obstruction in hypertrophic cardiomyopathy: from idiopathic hypertrophic subaortic stenosis to hypertrophic cardiomyopathy. J Am Coll Cardiol 2009;54:191-200.

3. Morrow AG, Brockenbrough EC. Surgical treatment of idiopathic hypertrophic subaortic stenosis: technic and hemodynamic results of subaortic ventriculomyotomy. Ann Surg 1961;154:181-89.

4. Morrow AG, Reitz BA, Epstein SE, et al. Operative treatment in hypertrophic subaortic stenosis. Techniques and the results of pre and postoperative assessments in 83 patients. Circulation 1975;52:88-102.

5. Minakata K, Dearani JA, Nishimura RA, et al. Extended septal myectomy for hypertrophic obstructive cardiomyopathy with anomalous mitral papillary muscles or chordae. J Thorac Cardiovasc Surg 2004;127:481-489.

6. Schaff HV, Said SM. Transaortic extended septal myectomy for hypertrophic cardiomyopathy. Op Tech Thor Cardiovas Surg 2012;17:238-250.

7. Maron BJ, Roberts WC. The father of septal myectomy for obstructive HCM, who also had HCM: the unbelievable story. J Am Coll Cardiol 2016;67:2900-3.

8. Firoozi S, Elliott PM, Sharma S, et al. Septal myotomymyectomy and transcoronary septal alcohol ablation in hypertrophic obstructive cardiomyopathy: a comparison of clinical, haemodynamic and exercise outcomes. Eur Heart 
J 2002;23:1617-24.

9. Yacoub MH. Surgical versus alcohol septal ablation for hypertrophic obstructive cardiomyopathy: the pendulum swings. Circulation 2005;112:450-452.

10. Maron BJ. Surgical myectomy remains the primary treatment option for severely symptomatic patients with obstructive hypertrophic cardiomyopathy. Circulation 2007;116:196-206.

11. Maron BJ, Yacoub M, Dearani JA. Benefits of surgery in obstructive hypertrophic cardiomyopathy: bring septal myectomy back for European patients. Eur Heart J 2011;32:1055-58.

12. Vriesendorp PA, Liebregts M, Steggerda RC, et al. Longterm outcomes after medical and invasive treatments in patients with hypertrophic cardiomyopathy. JACC Heart Fail 2014;2:630-6.

13. Maron BJ, McKenna WJ, Danielson GK, et al. A report of the American College of Cardiology Foundation Task Force on clinical expert consensus documents and the European Society of Cardiology committee for practice guidelines. J Am Coll Cardiol 2003;42:1687-713.

14. Gersh BJ, Maron BJ, Bonow RO, et al. 2011 ACCF/ AHA Guideline for the Diagnosis and Treatment of Hypertrophic Cardiomyopathy: a report of the American College of Cardiology Foundation/American Heart Association Task Force on Practice Guidelines. Developed in collaboration with the American Association for Thoracic Surgery, American Society of Echocardiography, American Society of Nuclear Cardiology, Heart Failure Society of America, Heart Rhythm Society, Society for Cardiovascular Angiography and Interventions, and Society of Thoracic Surgeons. J Am Coll Cardiol 2011;58:e212-60.

15. Spirito P, Maron BJ, Rosing DR. Morphologic determinants of hemodynamic state after ventricular septal myotomy - myectomy in patients with obstructive hypertrophic cardiomyopathy: M mode and twodimensional echocardiographic assessment. Circulation 1984;70:984-95.

16. Ommen SR, Maron BJ, Olivotto I, et al. Long-term effects of surgical septal myectomy on survival in patients with obstructive hypertrophic cardiomyopathy. J Am Coll Cardiol 2005;46:470-476.

17. Woo A, Williams WG, Choi R, et al. Clinical and echocardiographic determinants of long-term survival after surgical myectomy in obstructive hypertrophic cardiomyopathy. Circulation 2005;111:2033-41.

18. Smedira NG, Lytle BW, Lever HM, et al. Current effectiveness and risks of isolated septal myectomy for hypertrophic cardiomyopathy. Ann Thorac Surg 2008;85:127-33.

19. Ball $W$, Ivanov J, Rakowski $H$, et al. Long-term survival in patients with resting obstructive hypertrophic cardiomyopathy comparison of conservative versus invasive treatment. J Am Coll Cardiol 2011;58:2313-21.

20. Desai MY, Bhonsale A, Smedira NG, et al. Predictors of long-term outcomes in symptomatic hypertrophic cardiomyopathy patients undergoing surgical relief of left ventricular outflow tract obstruction. Circulation 2013;128:209-16.

21. Sedehi D, Finocchiaro G, Tibayan Y, et al. Long-term outcomes of septal reduction for obstructive hypertrophic cardiomyopathy. J Cardiol 2015;66:57-62.

22. Liebregts M, Vriesendorp PA, Mahmoodi BK, et al. A systematic review and meta-analysis of long-term outcomes after septal reduction therapy in patients with hypertrophic cardiomyopathy. JACC Heart Fail 2015;3:896-905.

23. Maron BJ, Dearani JA, Ommen SR, et al. Low operative mortality achieved with surgical septal myectomy: role of dedicated hypertrophic cardiomyopathy centers in the management of dynamic subaortic obstruction. J Am Coll Cardiol 2015;66:1307-8.

24. Maron BJ, Rastegar H, Udelson JE, et al. Contemporary surgical management of hypertrophic cardiomyopathy, the need for more myectomy surgeons and diseasespecific centers, and the Tufts initiative. Am J Cardiol 2013;112:1512-5.

25. Schulte HD, Bircks WH, Loesse B, et al. Prognosis of patients with hypertrophic obstructive cardiomyopathy after transaortic myectomy. Late results up to twenty-five years. J Thorac Cardiovasc Surg 1993;106:709-17.

26. Shahian DM, O'Brien SM, Filardo G, et al. Society of Thoracic Surgeons Quality Measurement Task Force. The Society of Thoracic Surgeons 2008 cardiac surgery risk models: part 1--coronary artery bypass grafting surgery. Ann Thorac Surg 2009;88:S2-22.

27. O'Brien SM, Shahian DM, Filardo G, et al. Society of Thoracic Surgeons Quality Measurement Task Force. The Society of Thoracic Surgeons 2008 cardiac surgery risk models: part 2--isolated valve surgery. Ann Thorac Surg 2009;88:S23-42.

28. Shahian DM, O'Brien SM, Filardo G, et al. The Society of Thoracic Surgeons 2008 cardiac surgery risk models: part 3 --valve plus coronary artery bypass grafting surgery. Ann Thorac Surg 2009;88:S43-62.

29. Rankin JS, He X, O'Brien SM, et al. The Society of 
Thoracic Surgeons risk model for operative mortality after multiple valve surgery. Ann Thorac Surg 2013;95:1484-90.

30. Iacovoni A, Spirito P, Simon C, et al. A contemporary European experience with surgical septal myectomy in hypertrophic cardiomyopathy. Eur Heart J 2012;33:2080-7.

31. Ferrazzi P, Spirito P, Iacovoni A, et al. Transaortic chordal cutting: mitral valve repair for obstructive hypertrophic cardiomyopathy with mild septal hypertrophy. J Am Coll Cardiol 2015;66:1687-96.

32. Wang S, Cui H, Yu Q, et al. Excision of anamolous muscle bundles as an important addition to extended septal myectomy for treatment of left ventricular outflow tract obstruction. J Thorac Cardiovasc Surg 2016;152:461-8.

33. Klues HG, Roberts WC, Maron BJ. Anomalous insertion of papillary muscle directly into anterior mitral leaflet in hypertrophic cardiomyopathy. Significance in producing left ventricular outflow obstruction. Circulation 1991;84:1188-97.

Cite this article as: Rastegar H, Boll G, Rowin EJ, Dolan N, Carroll C, Udelson JE, Wang W, Carpino P, Maron BJ, Maron MS, Chen FY. Results of surgical septal myectomy for obstructive hypertrophic cardiomyopathy: the Tufts experience. Ann Cardiothorac Surg 2017;6(4):353-363. doi: 10.21037/ acs.2017.07.07
34. Kim LK, Swaminathan RV, Looser P, et al. Hospital Volume outcomes after septal myectomy and alcohol septal ablation for treatment of obstructive hypertrophic cardiomyopathy: US nationwide inpatient database, 20032011. JAMA Cardiol 2016;1:324-32.

35. Ommen SR, Nishimura RA. Hypertrophic cardiomyopathy - one case per year?: A clarion call to do what is right. JAMA Cardiol 2016;1:333-4.

36. Schaff HV, Dearani JA, Ommen SR, et al. Expanding the indications for septal myetomy in patients with hypertrophic cardiomyopathy: results of operation in patients with latent obstruction. J Thorac Cardiovasc Surg 2012;143:303-9.

37. Maron BJ, Dearani JA, Maron MS, et al. Why We Need More Septal Myectomy Surgeons: An Emerging Recognition. J Thorac Cardiovasc Surg 2017. [Epub ahead of print]. 